\title{
Role of extracellular signal-regulated kinase and AKT cascades in regulating hypoxia-induced angiogenic factors produced by a trophoblast-derived cell line
}

\author{
Daisuke Fujita, Akiko Tanabe, Tatsuharu Sekijima, Hekiko Soen, Keijirou Narahara, Yoshiki Yamashita, \\ Yoshito Terai, Hideki Kamegai and Masahide Ohmichi
}

Department of Obstetrics and Gynecology, Osaka Medical College, 2-7 Daigaku-machi, Takatsuki-City, Osaka 569-8686, Japan

(Correspondence should be addressed to A Tanabe; Email: gyn074@poh.osaka-med.ac.jp)

\begin{abstract}
During human pregnancy, trophoblasts play an important role in embryo implantation and placental development. Cytotrophoblast cells invade the uterine spiral arteries and differentiate into extravillous trophoblasts, resulting in the remodeling of the uterine vessels and fetoplacental vasculature. During early pregnancy, a physiologically hypoxic environment induces the production of angiogenic factors, such as vascular endothelial growth factor (VEGF), which are suggested to locally control the vascular remodeling. Endoglin, a cell-surface coreceptor for transforming growth factor- $\beta 1$, is highly expressed in endothelial cells and syncytiotrophoblasts, and can be associated with endothelial nitric oxide synthase and vascular homeostasis. Several studies have recently suggested that some pregnancy-related complications, such as preeclampsia, have their origins early in pregnancy as a result of abnormalities in implantation and placental
\end{abstract}

development. Although angiogenic factors are recognized as key molecules in placental development, little is known about the mechanism(s) of their regulation in trophoblasts. In this study, we elucidated the mechanisms underlying the regulation of VEGF and endoglin production under hypoxic conditions in the trophoblast-derived cell line, BeWo. We evaluated the role of the AKT-MTOR cascade and ERK kinase in the expression of VEGF and endoglin in response to hypoxia using various kinase inhibitors and small interfering RNA targeted against hypoxia-inducible factor (HIF)- $1 \alpha$ (listed as HIF1A in Hugo Database). Our results suggest that both the phosphatidylinositol 3-kinase-AKTMTOR-HIF- $1 \alpha$ and ERK-HIF-1 $\alpha$ signaling pathways are crucial for increasing VEGF and endoglin expression in response to hypoxia in BeWo cells.

Journal of Endocrinology (2010) 206, 131-140

\section{Introduction}

During the first trimester of human pregnancy, extravillous trophoblasts from placental villi invade the deciduas and form plugs which temporarily occlude the spiral arteries and prevent maternal blood flow from entering the intervillous space, thereby creating a physiological low-oxygen environment (Jaffe et al. 1997, Burton et al. 1999). Rodesch et al. (1992) directly measured oxygen tension using a polarographic oxygen electrode during the first trimester of pregnancy. They demonstrated that the placenta develops in conditions of physiological hypoxia, in which the local oxygen concentration is as low as $1-2 \%$ during the first trimester. A significant increase was observed for placental $\mathrm{PO}_{2}$ values measured at 12-13 weeks compared with those obtained at $8-10$ weeks. More recently, Jauniaux et al. (2001) measured respiratory gases and acid-base gradients at 7-16 weeks of gestation. This report showed that before 11 weeks of gestation, the $\mathrm{PO}_{2}$ level in the placenta was 2.5 times lower than that in deciduas (Jauniaux et al. 2001). Near the end of the first trimester, the trophoblast plugs progressively loosen, exposing the developing placenta to the maternal blood flow from $\sim 10$ weeks of gestation (Jaffe \& Woods 1993, Jauniaux et al. 2003). Therefore, the placenta initially develops under conditions of physiological hypoxia, and it is believed that the low-oxygen condition regulates placental development and extravillous trophoblast outgrowth (James et al. 2006).

A variety of angiogenic growth factors, including vascular endothelial growth factor (VEGF), are expressed in the placenta (Park et al. 1994, Cooper et al. 1995). VEGF is a powerful endothelial cell mitogen, and supports angiogenic remodeling of the early vessels, stimulating the formation of a capillary network to the placenta (Demir et al. 2004). In primary human endothelial cells, hypoxia increases the mRNA and protein levels of VEGF via hypoxia-inducible factor (HIF)-1 $\alpha$ (listed as HIF1A in the Hugo Database) activation, which results in endothelial cell proliferation and tube formation (Yamakawa et al. 2003). VEGF has been implicated as playing an important role in placental angiogenesis (Ferrara et al. 2003, Zygmunt et al. 2003, Jauniaux et al. 2006).

Endoglin, a cell-surface coreceptor for transforming growth factor (TGF)- $\beta 1$ and TGF- $\beta 3$ isoforms, is highly 
expressed in endothelial cells and syncytiotrophoblasts (Cheifetz et al. 1992, Gougos et al. 1992, St-Jacques et al. 1994). Mutations in the gene encoding endoglin, ENG, are the underlying cause of hereditary hemorrhagic telangiectasia type 1 , an autosomal dominant disorder characterized by arteriovenous malformations and focal loss of capillaries (McAllister et al. 1994). Endoglin is predominantly expressed in endothelial cells and is up-regulated by hypoxia (Brekken et al. 2002, Sanchez-Elsner et al. 2002, Duff et al. 2003). Recently, it was found that endoglin localizes to caveolae, where it can associate with endothelial nitric oxide synthase (eNOS) and regulate the activity and local tone of the vasculature (Toporsian et al. 2005). These data suggest the involvement of endoglin not only in cardiovascular development, but also in vascular homeostasis.

Although hypoxia caused by incomplete trophoblast invasion and impaired spiral arterial remodeling is thought to be a major cause of preeclampsia (PE) and intrauterine growth restriction (IUGR; Zhou et al. 1997, 2003, Damsky \& Fisher 1998), how hypoxia affects placental development remains uncertain. Recent studies have implicated increased circulating soluble fms-like tyrosine kinase 1 (sFLT1, also known as soluble VEGF receptor 1) and soluble endoglin (sENG) as contributors to the pathogenesis of PE (Maynard et al. 2003, Levine et al. 2004, 2006, Venkatesha et al. 2006). The sFLT1 in the maternal circulation binds to VEGF and placental growth factor (PlGF), thereby preventing the action of these angiogenic growth factors on vascular tissues (Kendall et al. 1996, Maynard et al. 2003). Overexpression of $s F l t 1$ in rats leads to hypertension, proteinuria, and glomerular endotheliosis, the classical manifestations of $\mathrm{PE}$, suggesting that excess circulating sFLT1 may have a causal role in PE (Maynard et al. 2003). sENG has been shown to exert antiangiogenic properties, possibly via an impairment of TGF- $\beta 1$ signaling in the vasculature (Toporsian et al. 2005, Bernabeu et al. 2007). Moreover, sENG inhibits the formation of capillary tubes, and protein cooperates with sFLT1 to induce endothelial dysfunction in vitro, and a severe PE-like illness in vivo (Venkatesha et al. 2006). These findings suggest that both VEGF and endoglin may be crucial factors that must be strictly regulated to achieve normal placental development.

Little is known regarding the mechanisms that regulate VEGF and endoglin expression in the placenta; therefore, we elucidated the roles of the AKT-MTOR and ERK cascades in the regulation of VEGF and endoglin production under hypoxic conditions in the trophoblastderived cell line, BeWo.

\section{Materials and Methods}

\section{Materials}

The phosphatidylinositol 3-kinase (PI3K) inhibitor, LY294002, and MAPK kinase (MEK) inhibitor, PD98059, were purchased from Calbiochem (San Diego, CA, USA). The MTOR inhibitor, rapamycin, was purchased from
Sigma Chemical Co. Anti-ERK polyclonal antibodies, anti-phosphorylated ERK polyclonal antibodies, anti-AKT polyclonal antibodies, anti-phosphorylated AKT polyclonal antibodies, and anti-phosphorylated MTOR antibodies were obtained from Cell Signaling Technology, Inc. (Danvers, MA, USA). The anti-HIF- $1 \alpha$ monoclonal and anti-NFאB antibodies were obtained from Becton Dickinson (Franklin Lakes, NJ, USA).

\section{Cell culture}

The BeWo choriocarcinoma cell line was obtained from the American Type Culture Collection (Manassas, VA, USA). BeWo cells were cultured at $37^{\circ} \mathrm{C}$ in DMEM/F-12 with $10 \%$ FBS in a water-saturated atmosphere of $95 \% \mathrm{O}_{2}$ and $5 \% \mathrm{CO}_{2}$, unless otherwise indicated. Prior to treatment, BeWo cells were serum-starved in DMEM/F-12 medium containing $0 \cdot 5 \%$ BSA for $16 \mathrm{~h}$. Hypoxic exposure was carried out under $1 \% \mathrm{O}_{2}, 5 \% \mathrm{CO}_{2}$, and $94 \% \mathrm{~N}_{2}$ in a modular incubator (Hirasawa, Tokyo, Japan) for the times indicated in the figures (2-6 h). Inhibitors were added $1 \mathrm{~h}$ before hypoxia.

\section{Western blot analysis}

The BeWo cells were starved and incubated under hypoxic conditions for the times indicated in the figures. Cells were then washed twice with ice-cold PBS, lysed, and separated into cytoplasmic and nuclear fractions using a Nuclear Extract Kit according to the manufacturer's protocol (Active Motif, Carlsbad, CA, USA). The protein concentrations of the supernatants were determined using the Bio-Rad protein assay reagent. Equal amounts of proteins were separated by SDS-PAGE and transferred to nitrocellulose membranes. Blocking was done in 10\% BSA in $1 \times$ Tris-buffered saline. Western blot analyses were performed with various specific primary antibodies. Immunoreacted bands in the immunoblots were visualized with HRP-coupled goat anti-rabbit or anti-mouse immunoglobulin by using the enhanced chemiluminescence western blotting detection system.

\section{Real-time PCR}

Total RNA was isolated using a TRIzol-based approach, according to the manufacturer's protocol (Invitrogen), and the RNA was reverse-transcribed using the first-strand cDNA synthesis kit (Amersham Biosciences) as recommended. Real-time PCR was carried out using a Roche LightCycler 2.0 system (Roche Diagnostics). The synthesized cDNA was diluted to $20 \mathrm{ng} / \mu \mathrm{l}$ and used at $50 \mathrm{ng}$ per reaction. The Taqman Master kit, in combination with the Universal Probe Library (Human), was used to assess gene expression (Roche Diagnostics). PCR primers for Taqman/Probe Library assays were designed using the Probe Library Assay Design Center (https://www.roche-applied-science.com/ sis/rtpcr/upl/acenter.jsp?id =030000), and included the following: VEGF-specific primers $5^{\prime}$-TTG AGT TAA 
ACG AAC G-3' (forward) and $5^{\prime}$-GGT TCC CGA ACC CTG AG-3' (reverse); endoglin primers 5'-CCA CTG CAC TTG GCC TAC A-3' (forward) and $5^{\prime}$-GCC CAC TCA AGG ATC TGG-3' (reverse); HIF- $1 \alpha$ primers $5^{\prime}$-TTT TTC AAG CAG TAG GAA TTG GA-3' (forward) and $5^{\prime}$-GTG ATG TAG TAG CTG CAT GAT CG-3' (reverse); and GAPDH primers $5^{\prime}$-AGC CAC ATC GCT CAG ACA- $3^{\prime}$ (forward) and $5^{\prime}$-GCC CAA TAC GAC CAA ATC C- $3^{\prime}$ (reverse). Quantitative real-time PCR was performed using a LightCycler 2.0, and the data were analyzed by the LightCycler Software program 4.05 (Roche Diagnostics) using a calibrator-normalized relative quantification approach. Relative quantification was based on GAPDH expression.

\section{Small interfering $R N A$ expression}

The small interfering RNA (siRNA) against HIF- $1 \alpha$ (stealth RNAi) was custom synthesized (Invitrogen). Primer sequences were as follows: sense, 5'-GAG GAA ACU UCU GGA UGC UGG UGA T- $3^{\prime}$; antisense, 5'-AUC ACC AGC AUC CAG AAG UUU CCU C- $3^{\prime}$. Sequences of the stealth RNAi negative control (scrambled siRNA) were as follows: sense, 5'-GAG AAU CCU GUA GGU UCG GUA GGA U-3'; antisense, 5'-AUC CUA CCG AAC CUA CAG GAU UCU C- $3^{\prime}$. The siRNA and scrambled siRNA were transiently transfected for $24 \mathrm{~h}$ using LipofectAMINE Plus (Invitrogen), according to the manufacturer's protocol. Briefly, 50\% confluent BeWo cells were seeded and incubated overnight. For the transfection of each sample, oligomerLipofectAMINE Plus complexes were prepared as follows: $100 \mathrm{pmol}$ of siRNA oligomer were diluted in $250 \mu \mathrm{l}$ of OptiMEM (Invitrogen). LipofectAMINE Plus was mixed gently before use, and then a $5-\mu \mathrm{l}$ aliquot was diluted in $250 \mu \mathrm{l}$ of Opti-MEM, mixed gently, and incubated for $5 \mathrm{~min}$ at room temperature. After the 5-min incubation, the diluted oligomer was combined with the diluted LipofectAMINE Plus, mixed gently, and incubated for $20 \mathrm{~min}$ at room temperature. The oligomer-LipofectAMINE Plus complexes were added to each well containing cells and medium, and mixed gently by rocking the plate back and forth. The cells were incubated at $37^{\circ} \mathrm{C}$ in a $\mathrm{CO}_{2}$ incubator for $24 \mathrm{~h}$, and then cells were prepared for each assay.

\section{ELISA}

The cell culture medium from cells grown under various conditions was collected and used to determine the secretion of VEGF and endoglin using an ELISA kit (R\&D Systems, Minneapolis, MN, USA) according to the manufacturer's instructions.

\section{Chromatin immunoprecipitation}

Chromatin immunoprecipitation (ChIP) assays were carried out according to the manufacturer's protocol. Briefly, BeWo cells were cross-linked with $1 \% \mathrm{HCHO}$ for $10 \mathrm{~min}$.
Cell extracts were sonicated to sheer chromatin to an average size of $\sim 600 \mathrm{~kb}$. The extract was divided into aliquots, and antibodies were added to the aliquots at a 1:100 dilution for immunoprecipitation. An anti-rabbit IgG antibody was used as a negative control. After immunoprecipitation, an aliquot of each captured immunocomplex was subjected to western analysis to confirm that the captured chromatin contained the transcriptional co-regulator corresponding to the specific antibody that had been used for ChIP. For the remainder of the sample, cross-links in the immunoprecipitated chromatin were reversed by heating with proteinase $\mathrm{K}$ at $65^{\circ} \mathrm{C}$ overnight, and then DNA was purified using a MinElute Reaction Cleanup kit (Qiagen) and resuspended in $10 \mu \mathrm{l}$ of $1 \times$ TE. The purified ChIP-caputured DNA was analyzed by PCR. PCR amplifications were performed with the following specific primer pair for VEGF: 5'-AAG ACA TCT GGC GGA AAC C-3 $3^{\prime}$ (forward) and $5^{\prime}$-ACA ATT GGT CGC TAA CCG AG-3' (reverse). The PCR products were separated by electrophoresis on a $2 \%$ agarose gel.

\section{Statistical analysis}

Statistical analysis was performed using one-way ANOVA followed by a Tukey's post hoc test, and $P<0.05$ was considered to be significant. Data in figures are presented as the means \pm S.E.M.

\section{Results}

\section{Regulation of VEGF and endoglin by hypoxic stimuli}

To investigate the trophoblast response to a hypoxic stimulus, serum-starved BeWo cells were incubated under hypoxic conditions (1\% oxygen) for various times. Real-time PCR assays were performed to examine whether hypoxia up-regulated the expression of $V E G F$ and endoglin. We observed that VEGF mRNA expression was increased $1 \cdot 52 \pm 0 \cdot 38$-, $4 \cdot 05 \pm 0 \cdot 27$-, and $3 \cdot 13 \pm 0 \cdot 35$-fold at 2 , 4 , and $6 \mathrm{~h}$ respectively compared with cells incubated under normoxia (Fig. 1A). The endoglin mRNA expression increased $3 \cdot 64 \pm 0 \cdot 52$ - and $1 \cdot 51 \pm 0 \cdot 33$-fold at 4 and $6 \mathrm{~h}$ respectively in comparison to the cells incubated under normoxia (Fig. 1B).

\section{Differential activation of $A K T$ and ERK cascades by hypoxia}

We next examined whether hypoxia activates the AKT and ERK cascades in the BeWo cells. The cells were incubated under hypoxic conditions ( $1 \%$ oxygen) for various times, and then the lysates were analyzed by western blotting with an anti-phospho-AKT, -AKT, -phospho-MTOR, or -MTOR antibody. Although hypoxia did not affect the expression of AKT (Fig. 2A, lower panel), it induced a transient phosphorylation of AKT lasting 6-10 h, followed by a decrease in AKT phosphorylation (Fig. 2A, upper panel). Hypoxia also transiently increased the phosphorylation of the 

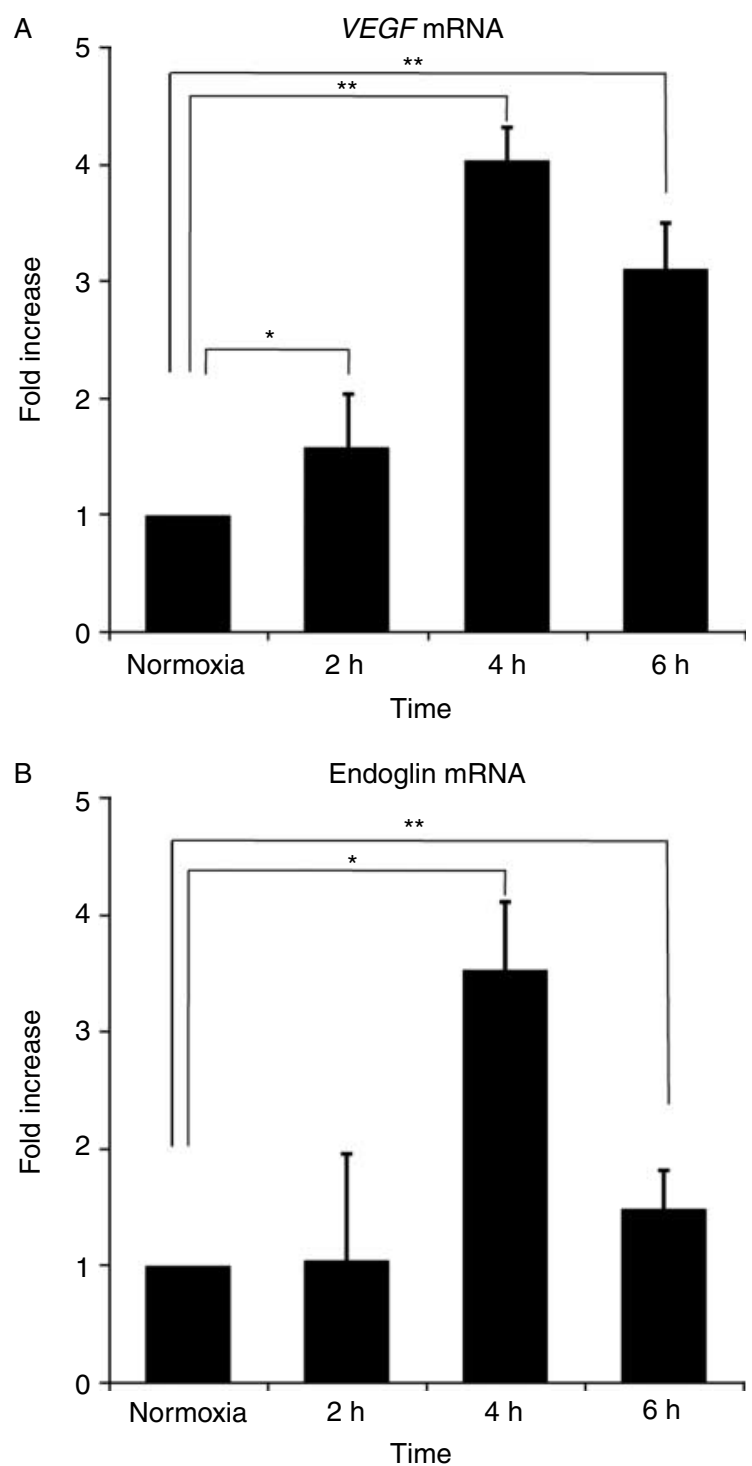

Figure 1 Effect of hypoxia on VEGFand endoglin mRNA expression in BeWo cells. BeWo cells were cultured in serum-free medium for $16 \mathrm{~h}$ and incubated under $1 \% \mathrm{O}_{2}$ for various times (indicated in the figure). Total RNA was isolated and reverse-transcribed, and then the resulting cDNA was used for real-time PCR to assess the mRNA expression of $\operatorname{VEGF}(\mathrm{A})$ and endoglin (B) relative to GAPDH. Values shown represent the means \pm S.E.M. from at least three separate experiments. Significant differences are indicated by asterisks. $* * P<0 \cdot 01$ and ${ }^{*} P<0 \cdot 05$.

substrate of AKT, MTOR, at $10 \mathrm{~h}$ in the BeWo cells (Fig. 2B, upper panel). Although hypoxia did not affect the expression of ERK (Fig. 2C, lower panel), the phosphorylation of ERK occurred at $6 \mathrm{~h}$ under hypoxic conditions, reached a plateau at $10 \mathrm{~h}$, and was sustained until $24 \mathrm{~h}$ in the BeWo cells (Fig. 2C, upper panel). These results demonstrate that hypoxia induces the phosphorylation of the AKT-MTOR cascade and ERK with different time courses of activation.
$A K T$ - and ERK-dependent expression of VEGF and endoglin induced by hypoxia

We observed that increased expression of VEGF and endoglin occurs under hypoxic conditions; however, the mechanisms underlying the hypoxia-induced increase in VEGF and endoglin expression were still unclear. Therefore, we investigated the AKT- and ERK-dependent expression of $V E G F$ and endoglin using kinase inhibitors. Cells were treated for $1 \mathrm{~h}$ with vehicle (DMSO), a PI3K inhibitor LY294002 (LY), the MTOR inhibitor rapamycin (Rapa), or the ERK inhibitor PD98059 (PD), and then exposed to hypoxia for $4 \mathrm{~h}$. Total RNA was isolated and reversetranscribed, and cDNA was used for real-time PCR. Whereas the vehicle (DMSO) had no effect on VEGF or endoglin mRNA expression, pretreatment with LY294002, rapamycin, and PD98059 attenuated the hypoxia-induced expression of both VEGF and endoglin mRNA (Fig. 3A and B). We next confirmed that the AKT and ERK kinases were involved in the expression of secreted VEGF and endoglin proteins using ELISA. Pretreatment with either LY294002, rapamycin, or PD98059 attenuated the hypoxia-induced increase in VEGF and endoglin secretion (Fig. 3C and D).

\section{Hypoxia recruits $H I F-1 \alpha$ to the promoters of VEGF and endoglin}

To examine whether hypoxia induces HIF- $1 \alpha$ translocation into the nucleus, cells were incubated under hypoxic conditions ( $1 \%$ oxygen) for various times, and then nuclear fractions and whole cell lysates were prepared for analysis by western blotting. HIF-1 $\alpha$ expression was increased in the nuclear fraction at 6 and $10 \mathrm{~h}$ under hypoxic conditions (Fig. 4A, upper panel). However, the expression of $H I F-1 \beta$ did not differ among the lanes in the nuclear fraction (Fig. 4A, middle panel), suggesting that hypoxia led to the translocation of HIF- $1 \alpha$ into the nucleus, but did not alter the expression of $H I F-1 \beta$. We next examined whether hypoxia enhances the binding of HIF- $1 \alpha$ to the promoters for VEGF and endoglin. The BeWo cells were incubated under hypoxic conditions (1\% oxygen) for various times, and then used to prepare lysates that were subjected to ChIP with an antibody against HIF-1 $\alpha$. The ChIP-captured DNA was subjected to PCR amplification using PCR primers located downstream and upstream of the $H I F-1 \alpha$-binding sites on the promoters for VEGF (Fig. 4B, upper panel) and endoglin (Fig. 4C, upper panel). The results indicated that hypoxia induced the translocation of HIF- $1 \alpha$ into the nucleus, and also increased the binding of HIF- $1 \alpha$ to the promoters of both VEGF and endoglin in these cells.

\section{Effect of HIF- $1 \alpha$ silencing on the expression of VEGF and} endoglin induced by hypoxia

To confirm that HIF- $1 \alpha$ was required for the induction of $V E G F$ and endoglin by hypoxia, we examined the effects of silencing HIF-1 $\alpha$ on the hypoxia-induced expression of 

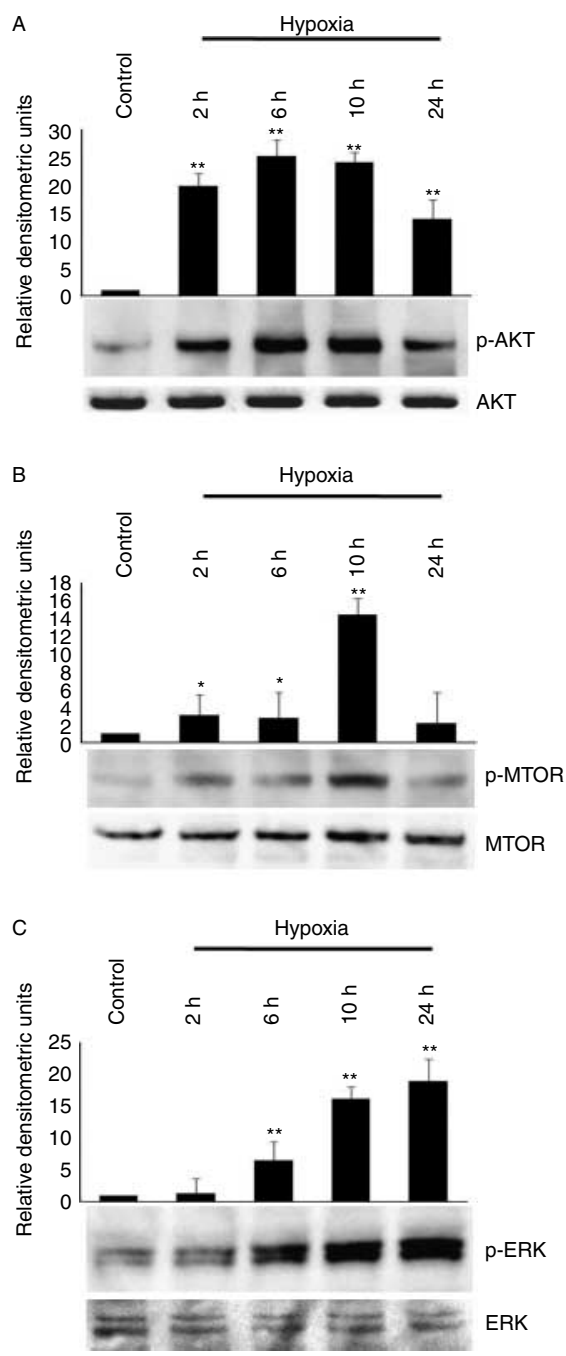

Figure 2 Hypoxia increases AKT, MTOR, and ERK phosphorylation in BeWo cells. BeWo cells were exposed to hypoxia for 0 (control) to $24 \mathrm{~h}$, and samples from the cytoplasmic fraction were subjected to western blotting for (A) phospho-AKT (upper panel) and AKT (lower panel), (B) phospho-MTOR (upper panel) and MTOR (lower panel), and (C) phospho-ERK (upper panel) and ERK (lower panel), with the density of the control bands set arbitararily at $1 \cdot 0$. Values shown represent the means \pm s.E.M. from at least three separate experiments. Significant differences are indicated by asterisks. ${ }^{* *} P<0 \cdot 01$ and ${ }^{*} P<0 \cdot 05$.

$V E G F$ and endoglin mRNA. Demonstrating that the siRNA was effective, the expression of $H I F-1 \alpha$ in BeWo cells transfected with the siRNA against HIF- $1 \alpha$ was found to be significantly lower than that in the BeWo cells transfected with the scrambled siRNA (Fig. 5A, upper panel). The specificity of the siRNA is illustrated by the equal expression of $\beta$-actin in cells transfected with both the specific and scrambled siRNAs (Fig. 5A, middle panel). We further confirmed the $H I F-1 \alpha$ silencing using quantitative real-time PCR. The expression of HIF- $1 \alpha$ was decreased $0 \cdot 3$ times in the BeWo cells transfected with siRNA (Fig. 5B).
The VEGF mRNA expression induced by hypoxia was increased $3 \cdot 23 \pm 0 \cdot 19$-fold in the BeWo cells transfected with scrambled siRNA; transfection with $H I F-1 \alpha$ siRNA significantly attenuated the $V E G F$ mRNA expression induced by hypoxia (Fig. 5C). Similarly, while the expression of endoglin mRNA induced by hypoxia was increased $2 \cdot 31 \pm 0 \cdot 35$-fold in BeWo cells transfected with the scrambled siRNA, transfection with $H I F-1 \alpha$ siRNA significantly attenuated the expression of endoglin mRNA (Fig. 5D). These results suggest that HIF-1 $\alpha$ is a necessary determinant of the hypoxia-induced expression of VEGF and endoglin in trophoblast-derived BeWo cells.

\section{Discussion}

Our study uncovered the signaling mechanism responsible for the hypoxia-induced release of angiogenic factors in BeWo cells. We have therefore demonstrated two major findings: i) hypoxia ( $1 \%$ oxygen) differentially induces both the mRNA expression and protein secretion of VEGF and endoglin via the AKT-MTOR and ERK signaling cascades and ii) $H I F-1 \alpha$ is a major inducer of the expression of both $V E G F$ and endoglin.

In early pregnancy, trophoblasts grow and develop to form the placenta under physiological hypoxia, where the various angiogenic factors are dramatically up-regulated. In PE, the trophoblasts fail to properly migrate and transform into a normal placenta (Zhou et al. 1997, 2003, Damsky \& Fisher 1998). These facts led us to examine the molecular mechanisms underlying the regulation of angiogenic factors in trophoblast cells. However, primary cultured trophoblasts are heterogeneous and are not suitable for the experiments performed in this study, such as the transfection of siRNA. Therefore, in our study, we used trophoblast-derived human BeWo cells as a trophoblast model. These cells are similar in morphology to primary trophoblast cultures, and they are well established as an in vitro model to study trophoblast development and function (Ellinger et al. 1999, Heaton et al. 2008, Neelima \& Rao 2008).

Normally, trophoblast cells transform from an epithelial phenotype to an endothelial phenotype as they invade the maternal deciduas and myometrium in a process termed pseudovasculogenesis. Migrating trophoblasts transform the maternal spiral arterioles that supply maternal blood to the placenta from small caliber resistance vessels to large caliber capacitance vessels, allowing adequate maternal blood flow to the placenta (Starzyk et al. 1997, Lyall 2005). The epidermal growth factor was reported to induce syncytialization of cytotrophoblasts and the secretion of human chorionic gonadotropin and human placental lactogen in vitro (Morrish et al. 1987). Colony-stimulating factor (CSF), granulocytemacrophage CSF (GM-CSF), a TGF- $\beta$ superfamily member, as well as VEGF, have been described to promote the syncytialization of trophoblasts (Garcia-Lloret et al. 1994, Crocker et al. 2001, Yang et al. 2003a, Li et al. 2005). 


\section{A VEGF mRNA}

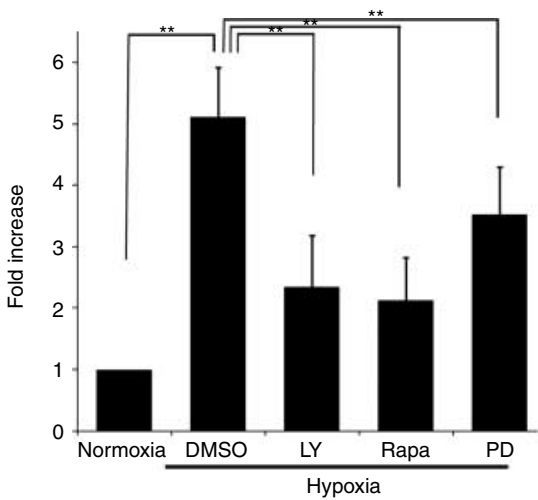

C

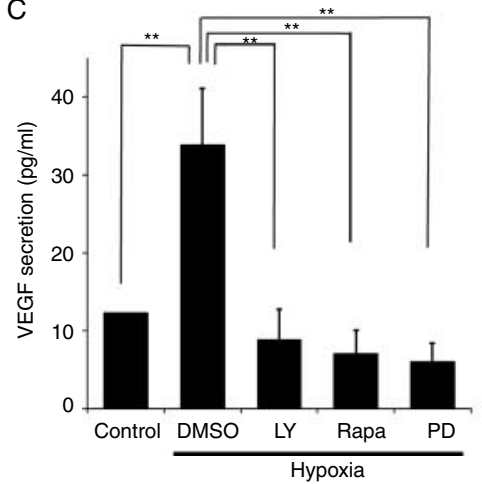

B Endoglin mRNA

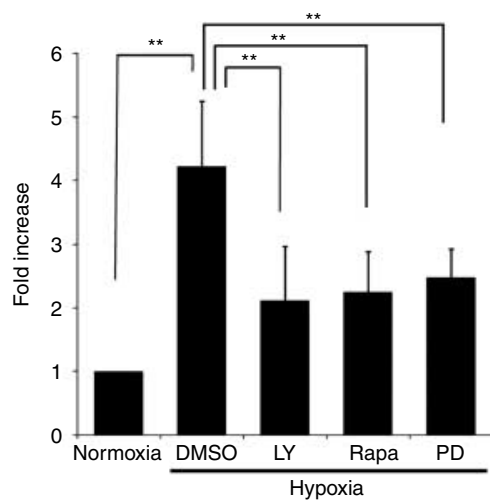

D

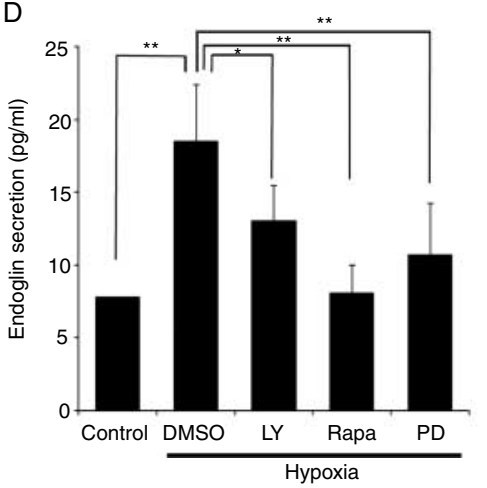

Figure 3 Role of AKT and ERK kinases on hypoxia-induced VEGF and endoglin mRNA in BeWo cells. BeWo cells were incubated in serum-free medium for $16 \mathrm{~h}$ and then for $30 \mathrm{~min}$ in the presence or in the absence of either $50 \mathrm{nM}$ LY294002 (LY), $50 \mathrm{nM}$ rapamycin (Rapa), $50 \mathrm{nM}$ PD98059 (PD), or $50 \mathrm{nM} \mathrm{LY}+50 \mathrm{nM}$ PD prior to incubation in a $1 \% \mathrm{O}_{2}$ hypoxic chamber for $4 \mathrm{~h}$. Total RNA was isolated and reverse-transcribed, and then the resulting CDNA was used for real-time PCR to measure the mRNA expression of VEGF (A) and endoglin (B) relative to GAPDH. Cell culture media were collected and used to determine the level of secreted VEGF (C) and endoglin (D) using ELISA kits. Values shown represent the means \pm S.E.M. from at least three separate experiments. Significant differences are indicated by asterisks. ${ }^{* *} P<0 \cdot 01 ;{ }^{*} P<0 \cdot 05$.

Our current results show that a hypoxic environment induces both VEGF and endoglin expression (Fig. 1) in a trophoblastderived cell line. However, the role of physiological hypoxia in early pregnancy and placental development is unclear, and the signaling mechanisms regulating the hypoxia-induced expression of angiogenic factors have not been fully investigated.

Our study demonstrates that AKT-MTOR activation is crucial for the production of angiogenic factors under hypoxic conditions in BeWo trophoblast-derived cells (Fig. 3). Recent studies have shown that PI3K and AKT play an important role in regulating tumor growth and angiogenesis through the upregulation of VEGF and HIF-1 expression. The central role of AKT signaling in placental growth regulation was confirmed in AKT1-null mice, which display IUGR (Yang et al. 2003b, Yung et al. 2008). Together, these studies demonstrated that the inactivation of AKT caused hypotrophy and structural abnormalities of the placenta that likely contributed to placental insufficiency and subsequent impairment of fetal growth.

Of interest, inhibition of PI3K/AKT/MTOR signaling in endothelial cells by rapamycin reverses the pathological effects associated with excess VEGF signaling in the tumor vasculature by either reducing AKT activity or blocking MTOR (Phung et al. 2006). It has been demonstrated that MTOR, which is a substrate of AKT, is essential for the growth and proliferation of early mouse embryonic stem cells (Gangloff et al. 2004, Murakami et al. 2004). Embryos that are MTOR deficient die shortly after implantation as a result of impaired cell proliferation in both the embryonic and extraembryonic compartments. These findings suggest that MTOR may play an important role in controlling trophoblast cell growth and proliferation (Wen et al. 2005). In order to investigate the physiological roles of VEGF and endoglin secreted from trophoblasts, co-culture methods with endothelial progenitor cells will be needed, and the morphological 
A

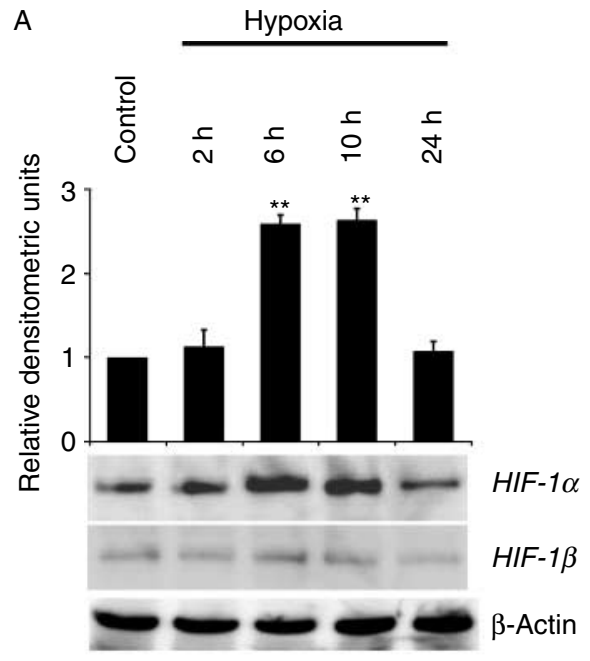

B

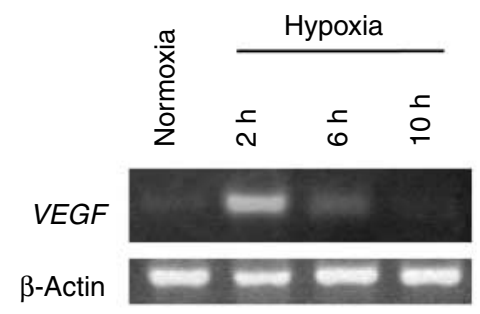

Chlp: anti-HIF-1 $\alpha$

C

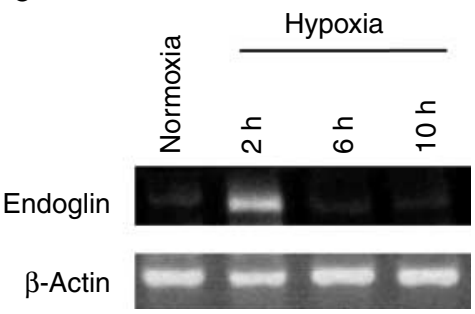

Figure $4 \mathrm{HIF}-1 \alpha / \beta$ is translocated into the nucleus and recruited to the VEGF promoter by hypoxia. (A) BeWo cells were exposed to $1 \% \mathrm{O}_{2}$ for 0 (control) to $24 \mathrm{~h}$, and samples from nuclear fractions were subjected to western blotting for HIF-1 $\alpha$ (upper panel) and HIF-1 $\beta$ (middle panel). Whole cell lysates were also evaluated for HIF expression, and the level of $\beta$-actin was detected as an internal loading control (lower panel). Relative densitometric units of the HIF- $1 \alpha$ bands are shown in the top panel, with the density of the control bands set arbitararily at $1 \cdot 0$. Values shown represent the means \pm s.E.M. from at least three separate experiments. Significant differences are indicated by asterisks $(* * P<0 \cdot 01)$. BeWo cells were exposed to $1 \% \mathrm{O}_{2}$ for 0 (control) to $10 \mathrm{~h}$, and lysates were chromatin immunoprecipitated with an antibody against HIF-1 $\alpha$. (B) The chromatin immunoprecipitation-captured DNA was subjected to PCR amplification using PCR primers located downstream and upstream of the HRE site of the promoter for VEGF (upper panel). PCRs using primers for $\beta$-actin were carried out using total cell extracts as an internal control. (C) The chromatin immunoprecipitation-captured DNA was subjected to PCR amplification using PCR primers located downstream and upstream of the HRE site of the promoter for endoglin (upper panel). PCRs using primers for $\beta$-actin were carried out using total cell extracts as an internal control (lower panel).

changes in BeWo or other trophoblast cells should be addressed by detecting differentiation, as well as examining migration and invasion.

The present study provides evidence that hypoxia induces the expression of angiogenic factors such as VEGF and endoglin via the AKT and ERK cascades, thus leading to the transcriptional activation of HIF- $1 \alpha$ in BeWo cells. HIF- $1 \alpha$ is a transcription factor which is activated by hypoxia, and is involved in the adaptative response of cells to oxygen deprivation. During hypoxic stress, HIF- $1 \alpha$ triggers the overexpression of genes coding for glycolytic enzymes and angiogenic factors (Diaz-Gonzalez et al. 2005). HIF-1 $\alpha$ is a substrate for various kinase pathways, including PI3K and the MAP kinases, ERK and p38 (Minet et al. 2001). Previous studies have demonstrated that the activation of AKT signaling in endothelial cells results in vessel relaxation via increases in eNOS activity (Luo et al. 2000, Hisamoto et al. 2001a,b, Northcott et al. 2002). Hypoxia was also shown to regulate eNOS activity and NO production via AKT activation in porcine coronary artery endothelial cells (Chen $\&$ Meyrick 2004). On the other hand, hypoxia increases the phosphorylation of ERK, followed by the stabilization and activation of $H I F-1 \alpha$ which enhances $H I F-1 \alpha$-dependent transcriptional activation of VEGF in hamster fibroblasts (Berra et al. 2000). Although siRNA targeted against HIF-1 $\alpha$ significantly blocked the secretion of VEGF and endoglin in our study, the involvement of other transcription factors should be investigated to obtain a better understanding of the full signaling pathway(s).

During PE, the fetal trophoblasts fail to properly invade the maternal myometrium and spiral arterioles (Meekins et al. 1994). The mechanisms underlying normal and failed trophoblast invasion are still poorly understood. In PE, major uteroplacental pathology is characterized by the coexistence of poor arterial remodeling (Pijnenborg et al. 1991) and minimal invasion of the deciduas and its vessels by extravillous trophoblast cells, which also fail to develop a vascular endothelial phenotype (Zhou et al. 1997). There is no 
A

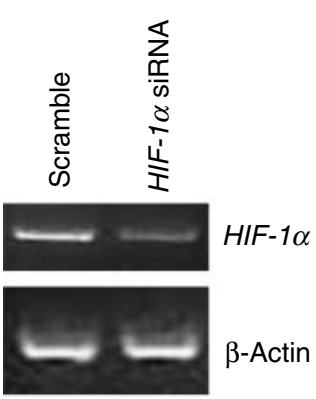

B

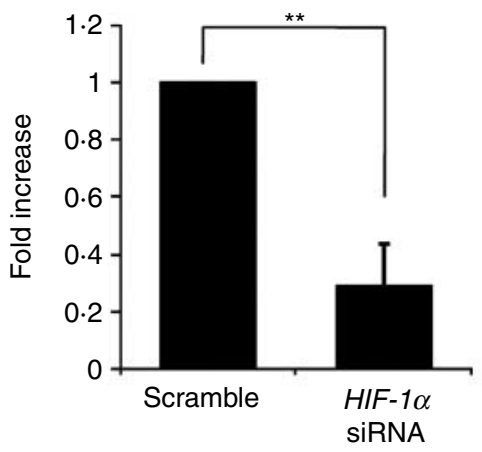

C

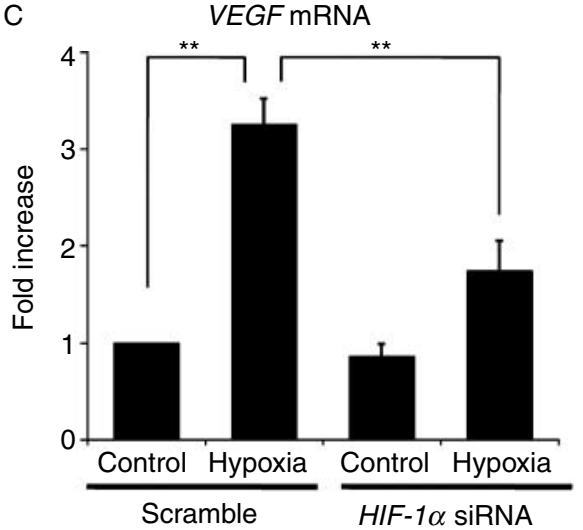

D

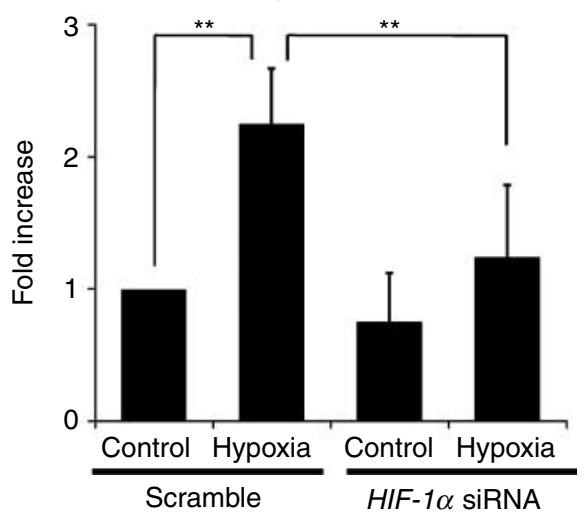

Figure 5 Effect of HIF- $1 \alpha$ silencing on hypoxia-induced expression of VEGF and endoglin mRNA. BeWo cells were transfected with scrambled or HIF-1 $\alpha$-specific siRNA as described in the Materials and Methods section. RNA was extracted from the cells, and RT-PCR assays were performed to detect the mRNA expression of HIF-1 $\alpha$ (A, upper panel) and $\beta$-actin (A, lower panel). Quantitative real-time PCR assays were performed to measure HIF-1 $\alpha$ (B) relative to GAPDH. Values shown represent the means \pm s.E.M. from at least three separate experiments. Significant differences are indicated by asterisks $\left({ }^{* *} P<0 \cdot 01\right)$. To determine the effect of HIF- $1 \alpha$ silencing on hypoxia-induced VEGFand endoglin mRNA expression, BeWo cells were transfected with scrambled or HIF-1 $\alpha$-specific siRNA as described in the Materials and Methods section. Total RNA was collected and reverse-transcribed, and then the resulting CDNA was used for real-time PCR to measure the mRNA expression of VEGF (C) and endoglin (D) relative to GAPDH. Values shown represent the means \pm s.E.M. from at least three separate experiments. Significant differences are indicated by asterisks ( $* * P<0 \cdot 01)$.

ideal model for human placentation, because the human placenta is unique compared to that of most other mammals. However, the linkage between placental hypoxia and maternal vascular dysfunction has been proposed to occur via placental syncytiotrophoblast basement membranes shed by the placenta or via placental secretion of angiogenic factors such as sFlt1 and endoglin that bind VEGF and PlGF in the maternal circulation. Therefore, the mechanisms that initiate $\mathrm{PE}$ in humans have been elusive, but some parts of the puzzle have begun to come together. In addition, although there have been several reports suggesting that hypoxia induces the expression of endoglin in PE (Levine et al. 2006, Venkatesha et al. 2006), the details about this mechanism remain uncertain. Therefore, further investigations will be necessary to clarify the physiological roles of VEGF and endoglin secreted from trophoblasts. In addition, in vivo studies are expected to provide insight into the importance of these pathways in placental formation and their role in PE.

In summary, the present study provides the first evidence that both the AKT/MTOR and ERK signaling pathways are involved in hypoxia-induced expression of both VEGF and endoglin in trophoblast-derived BeWo cells. Although no in vitro model provides a perfect approach for directly examining early placentation or the pathogenesis of $\mathrm{PE}$, our findings show that these mechanisms are likely to be necessary for placental development in early pregnancy, and may also have important implications for understanding the pathogenesis of PE. 


\section{Declaration of interest}

The authors declare that there is no conflict of interest that could be perceived as prejudicing the impartiality of the research reported.

\section{Funding}

This research did not receive any specific grant from any funding agency in the public, commercial, or not-for-profit sector.

\section{Acknowledgements}

We are grateful to Junko Hayashi and Kumiko Satoh for secretarial assistance.

\section{References}

Bernabeu C, Conley BA \& Vary CP 2007 Novel biochemical pathways of endoglin in vascular cell physiology. Journal of Cellular Biochemistry 102 1375-1388.

Berra E, Pages G \& Pouyssegur J 2000 MAP kinases and hypoxia in the control of VEGF expression. Cancer Metastasis Reviews 19 139-145.

Brekken RA, Li C \& Kumar S 2002 Strategies for vascular targeting in tumors. International Journal of Cancer 100 123-130.

Burton GJ, Jauniaux E \& Watson AL 1999 Maternal arterial connections to the placental intervillous space during the first trimester of human pregnancy: the Boyd collection revisited. American Journal of Obstetrics and Gynecology 181 718-724.

Cheifetz S, Bellon T, Cales C, Vera S, Bernabeu C, Massague J \& Letarte M 1992 Endoglin is a component of the transforming growth factor-beta receptor system in human endothelial cells. Journal of Biological Chemistry 267 19027-19030.

Chen JX \& Meyrick B 2004 Hypoxia increases Hsp90 binding to eNOS via PI3K-Akt in porcine coronary artery endothelium. Laboratory Investigation 84 182-190.

Cooper JC, Sharkey AM, McLaren J, Charnock-Jones DS \& Smith SK 1995 Localization of vascular endothelial growth factor and its receptor, flt, in human placenta and decidua by immunohistochemistry. Journal of Reproduction and Fertility 105 205-213.

Crocker IP, Strachan BK, Lash GE, Cooper S, Warren AY \& Baker PN 2001 Vascular endothelial growth factor but not placental growth factor promotes trophoblast syncytialization in vitro. Journal of the Society for Gynecologic Investigation 8 341-346.

Damsky CH \& Fisher SJ 1998 Trophoblast pseudo-vasculogenesis: faking it with endothelial adhesion receptors. Current Opinion in Cell Biology 10 660-666.

Demir R, Kayisli UA, Seval Y, Celik-Ozenci C, Korgun ET, Demir-Weusten AY \& Huppertz B 2004 Sequential expression of VEGF and its receptors in human placental villi during very early pregnancy: differences between placental vasculogenesis and angiogenesis. Placenta 25 560-572.

Diaz-Gonzalez JA, Russell J, Rouzaut A, Gil-Bazo I \& Montuenga L 2005 Targeting hypoxia and angiogenesis through HIF-1alpha inhibition. Cancer Biology and Therapy 4 1055-1062.

Duff SE, Li C, Garland JM \& Kumar S 2003 CD105 is important for angiogenesis: evidence and potential applications. FASEB Journal 17 984-992.

Ellinger I, Schwab M, Stefanescu A, Hunziker W \& Fuchs R 1999 IgG transport across trophoblast-derived BeWo cells: a model system to study IgG transport in the placenta. European Journal of Immunology 29 733-744.

Ferrara N, Gerber HP \& LeCouter J 2003 The biology of VEGF and its receptors. Nature Medicine 9 669-676.

Gangloff YG, Mueller M, Dann SG, Svoboda P, Sticker M, Spetz JF, Um SH, Brown EJ, Cereghini S, Thomas G et al. 2004 Disruption of the mouse
mTOR gene leads to early postimplantation lethality and prohibits embryonic stem cell development. Molecular and Cellular Biology 24 9508-9516.

Garcia-Lloret MI, Morrish DW, Wegmann TG, Honore L, Turner AR \& Guilbert LJ 1994 Demonstration of functional cytokine-placental interactions: CSF-1 and GM-CSF stimulate human cytotrophoblast differentiation and peptide hormone secretion. Experimental Cell Research 214 46-54.

Gougos A, St Jacques S, Greaves A, O'Connell PJ, d'Apice AJ, Buhring HJ, Bernabeu C, van Mourik JA \& Letarte M 1992 Identification of distinct epitopes of endoglin, an RGD-containing glycoprotein of endothelial cells, leukemic cells, and syncytiotrophoblasts. International Immunology 4 83-92.

Heaton SJ, Eady JJ, Parker ML, Gotts KL, Dainty JR, Fairweather-Tait SJ, McArdle HJ, Srai KS \& Elliott RM 2008 The use of BeWo cells as an in vitro model for placental iron transport. American Journal of Physiology. Cell Physiology 295 C1445-C1453.

Hisamoto K, Ohmichi M, Kanda Y, Adachi K, Nishio Y, Hayakawa J, Mabuchi S, Takahashi K, Tasaka K, Miyamoto Y et al. 2001a Induction of endothelial nitric-oxide synthase phosphorylation by the raloxifene analog LY117018 is differentially mediated by Akt and extracellular signalregulated protein kinase in vascular endothelial cells. Journal of Biological Chemistry 276 47642-47649.

Hisamoto K, Ohmichi M, Kurachi H, Hayakawa J, Kanda Y, Nishio Y, Adachi K, Tasaka K, Miyoshi E, Fujiwara N et al. 2001b Estrogen induces the Akt-dependent activation of endothelial nitric-oxide synthase in vascular endothelial cells. Journal of Biological Chemistry 276 3459-3467.

Jaffe R \& Woods JR Jr 1993 Color Doppler imaging and in vivo assessment of the anatomy and physiology of the early uteroplacental circulation. Fertility and Sterility $60293-297$.

Jaffe R, Jauniaux E \& Hustin J 1997 Maternal circulation in the first-trimester human placenta - myth or reality? American Journal of Obstetrics and Gynecology 176 695-705.

James JL, Stone PR \& Chamley LW 2006 The regulation of trophoblast differentiation by oxygen in the first trimester of pregnancy. Human Reproduction Update 12 137-144.

Jauniaux E, Watson A \& Burton G 2001 Evaluation of respiratory gases and acid-base gradients in human fetal fluids and uteroplacental tissue between 7 and 16 weeks' gestation. American Journal of Obstetrics and Gynecology 184 998-1003.

Jauniaux E, Hempstock J, Greenwold N \& Burton GJ 2003 Trophoblastic oxidative stress in relation to temporal and regional differences in maternal placental blood flow in normal and abnormal early pregnancies. American Journal of Pathology 162 115-125.

Jauniaux E, Poston L \& Burton GJ 2006 Placental-related diseases of pregnancy: involvement of oxidative stress and implications in human evolution. Human Reproduction Update 12 747-755.

Kendall RL, Wang G \& Thomas KA 1996 Identification of a natural soluble form of the vascular endothelial growth factor receptor, FLT-1, and its heterodimerization with KDR. Biochemical and Biophysical Research Communications 226 324-328.

Levine RJ, Maynard SE, Qian C, Lim KH, England LJ, Yu KF, Schisterman EF, Thadhani R, Sachs BP, Epstein FH et al. 2004 Circulating angiogenic factors and the risk of preeclampsia. New England Journal of Medicine $\mathbf{3 5 0}$ 672-683.

Levine RJ, Lam C, Qian C, Yu KF, Maynard SE, Sachs BP, Sibai BM, Epstein FH, Romero R, Thadhani R et al. 2006 Soluble endoglin and other circulating antiangiogenic factors in preeclampsia. New England Journal of Medicine 355 992-1005.

Li H, Dakour J, Guilbert LJ, Winkler-Lowen B, Lyall F \& Morrish DW 2005 PL74 a novel member of the transforming growth factor-beta superfamily, is overexpressed in preeclampsia and causes apoptosis in trophoblast cells. Journal of Clinical Endocrinology and Metabolism 90 3045-3053.

Luo Z, Fujio Y, Kureishi Y, Rudic RD, Daumerie G, Fulton D, Sessa WC \& Walsh K 2000 Acute modulation of endothelial Akt/PKB activity alters nitric oxide-dependent vasomotor activity in vivo. Journal of Clinical Investigation 106 493-499.

Lyall F 2005 Priming and remodelling of human placental bed spiral arteries during pregnancy - a review. Placenta 26 S31-S36. 
Maynard SE, Min JY, Merchan J, Lim KH, Li J, Mondal S, Libermann TA, Morgan JP, Sellke FW, Stillman IE et al. 2003 Excess placental soluble fmslike tyrosine kinase 1 (sFlt1) may contribute to endothelial dysfunction, hypertension, and proteinuria in preeclampsia. Journal of Clinical Investigation 111 649-658.

McAllister KA, Grogg KM, Johnson DW, Gallione CJ, Baldwin MA, Jackson CE, Helmbold EA, Markel DS, McKinnon WC, Murrell J et al. 1994 Endoglin, a TGF-beta binding protein of endothelial cells, is the gene for hereditary haemorrhagic telangiectasia type 1. Nature Genetics 8 345-351.

Meekins JW, Pijnenborg R, Hanssens M, McFadyen IR \& van Asshe A 1994 A study of placental bed spiral arteries and trophoblast invasion in normal and severe pre-eclamptic pregnancies. British Journal of Obstetrics and Gynaecology 101 669-674.

Minet E, Michel G, Mottet D, Raes M \& Michiels C 2001 Transduction pathways involved in hypoxia-inducible factor-1 phosphorylation and activation. Free Radical Biology and Medicine 31 847-855.

Morrish DW, Bhardwaj D, Dabbagh LK, Marusyk H \& Siy O 1987 Epidermal growth factor induces differentiation and secretion of human chorionic gonadotropin and placental lactogen in normal human placenta. Journal of Clinical Endocrinology and Metabolism 65 1282-1290.

Murakami M, Ichisaka T, Maeda M, Oshiro N, Hara K, Edenhofer F, Kiyama H, Yonezawa K \& Yamanaka S 2004 mTOR is essential for growth and proliferation in early mouse embryos and embryonic stem cells. Molecular and Cellular Biology 24 6710-6718.

Neelima PS \& Rao AJ 2008 Gene expression profiling during Forskolin induced differentiation of BeWo cells by differential display RT-PCR. Molecular and Cellular Endocrinology 281 37-46.

Northcott CA, Poy MN, Najjar SM \& Watts SW 2002 Phosphoinositide 3-kinase mediates enhanced spontaneous and agonist-induced contraction in aorta of deoxycorticosterone acetate-salt hypertensive rats. Circulation Research 91 360-369.

Park JE, Chen HH, Winer J, Houck KA \& Ferrara N 1994 Placenta growth factor. Potentiation of vascular endothelial growth factor bioactivity, in vitro and in vivo, and high affinity binding to Flt-1 but not to Flk-1/KDR. Journal of Biological Chemistry 269 25646-25654.

Phung TL, Ziv K, Dabydeen D, Eyiah-Mensah G, Riveros M, Perruzzi C, Sun J, Monahan-Earley RA, Shiojima I, Nagy JA et al. 2006 Pathological angiogenesis is induced by sustained Akt signaling and inhibited by rapamycin. Cancer Cell 10 159-170.

Pijnenborg R, Anthony J, Davey DA, Rees A, Tiltman A, Vercruysse L \& van Assche A 1991 Placental bed spiral arteries in the hypertensive disorders of pregnancy. British Journal of Obstetrics and Gynaecology 98 648-655.

Rodesch F, Simon P, Donner C \& Jauniaux E 1992 Oxygen measurements in endometrial and trophoblastic tissues during early pregnancy. Obstetrics and Gynecology 80 283-285.

Sanchez-Elsner T, Botella LM, Velasco B, Langa C \& Bernabeu C 2002 Endoglin expression is regulated by transcriptional cooperation between the hypoxia and transforming growth factor-beta pathways. Journal of Biological Chemistry 277 43799-43808.
Starzyk KA, Salafia CM, Pezzullo JC, Lage JM, Parkash V, Vercruysse L, Hanssens M \& Pijnenborg R 1997 Quantitative differences in arterial morphometry define the placental bed in preeclampsia. Human Pathology 28 353-358.

St-Jacques S, Forte M, Lye SJ \& Letarte M 1994 Localization of endoglin, a transforming growth factor-beta binding protein, and of CD44 and integrins in placenta during the first trimester of pregnancy. Biology of Reproduction 51 405-413.

Toporsian M, Gros R, Kabir MG, Vera S, Govindaraju K, Eidelman DH, Husain M \& Letarte M 2005 A role for endoglin in coupling eNOS activity and regulating vascular tone revealed in hereditary hemorrhagic telangiectasia. Circulation Research 96 684-692.

Venkatesha S, Toporsian M, Lam C, Hanai J, Mammoto T, Kim YM, Bdolah Y, Lim KH, Yuan HT, Libermann TA et al. 2006 Soluble endoglin contributes to the pathogenesis of preeclampsia. Nature Medicine 12 642-649.

Wen HY, Abbasi S, Kellems RE \& Xia Y 2005 mTOR: a placental growth signaling sensor. Placenta 26 S63-S69.

Yamakawa M, Liu LX, Date T, Belanger AJ, Vincent KA, Akita GY, Kuriyama T, Cheng SH, Gregory RJ \& Jiang C 2003 Hypoxia-inducible factor-1 mediates activation of cultured vascular endothelial cells by inducing multiple angiogenic factors. Circulation Research 93 664-673.

Yang M, Lei ZM \& Rao Ch V 2003a The central role of human chorionic gonadotropin in the formation of human placental syncytium. Endocrinology 144 1108-1120.

Yang ZZ, Tschopp O, Hemmings-Mieszczak M, Feng J, Brodbeck D, Perentes E \& Hemmings BA 2003b Protein kinase B alpha/Akt1 regulates placental development and fetal growth. Journal of Biological Chemistry 278 32124-32131.

Yung HW, Calabrese S, Hynx D, Hemmings BA, Cetin I, Charnock-Jones DS \& Burton GJ 2008 Evidence of placental translation inhibition and endoplasmic reticulum stress in the etiology of human intrauterine growth restriction. American Journal of Pathology 173 451-462.

Zhou Y, Damsky CH \& Fisher SJ 1997 Preeclampsia is associated with failure of human cytotrophoblasts to mimic a vascular adhesion phenotype. One cause of defective endovascular invasion in this syndrome? Journal of Clinical Investigation 99 2152-2164.

Zhou Y, Bellingard V, Feng KT, McMaster M \& Fisher SJ 2003 Human cytotrophoblasts promote endothelial survival and vascular remodeling through secretion of Ang2, PlGF, and VEGF-C. Developmental Biology 263 $114-125$.

Zygmunt M, Herr F, Munstedt K, Lang U \& Liang OD 2003 Angiogenesis and vasculogenesis in pregnancy. European Journal of Obstetrics, Gynecology, and Reproductive Biology 110 S10-S18.

\section{Received in final form 24 March 2010 \\ Accepted 6 April 2010}

Made available online as an Accepted Preprint 6 April 2010 